\title{
Effects of spike-time dependent plasticity on deep brain stimulation of the basal ganglia for treatment of Parkinson's disease
}

\author{
Logan L Grado ${ }^{1 *}$, Matthew D Johnson ${ }^{1,2}$, Theoden I Netoff ${ }^{1}$ \\ From 24th Annual Computational Neuroscience Meeting: CNS*2015 \\ Prague, Czech Republic. 18-23 July 2015
}

Deep brain stimulation (DBS) of the basal ganglia is a widely used and effective treatment for patients with medication-refractory Parkinson's disease (PD). However, tuning the stimulation parameters to maximize therapy while minimizing side effects is performed mostly through a trial and error approach, consuming time and energy of both clinician and patient [1]. As such, there is a need for a systematic, engineering based approach to improve patient outcomes. Current theories of DBS mechanisms propose that DBS suppresses pathological oscillations $(15-35 \mathrm{~Hz})$ that dominate the basal ganglia by suppressing information flow $[2,3]$. However, effects of DBS are not instant, often taking minutes or more before an effect is seen [4]. This time scale suggests DBS may induce a change in network architecture through synaptic plasticity, destabilizing oscillations in the network. Recently, a new approach to DBS called "Coordinated Reset" appears to take advantage of this phenomenon, resulting in therapeutic benefits that last from hours to days $[5,6]$. We hypothesize that if beta oscillations are indeed responsible for Parkinsonian signs, then the dissipation and return of these oscillations should follow a time course similar to that of the symptoms themselves. We use a computational network model of PD with emergent pathological $34 \mathrm{~Hz}$ oscillation developed by Hahn \& McIntyre [7] to test the effects of DBS on the basal ganglia, implemented with spike-time dependent plasticity (STDP) as described by Badoual et al. [8]. Preliminary results show that with the introduction of STDP, pathological beta oscillations dissipate over time after the onset of DBS stimulation in computational models. This

\footnotetext{
* Correspondence: grado010@umn.edu

'Graduate Program in Biomedical Engineering, University of Minnesota, Minneapolis, MN 55455, USA

Full list of author information is available at the end of the article
}

work suggests that it may be possible to tune stimulation settings to take advantage of long term plasticity effects in DBS to improve patient outcomes.

\section{Acknowledgements}

Research supported by Neuroengineering NSF IGERT under DGE-1069104

\section{Authors' details}

${ }^{1}$ Graduate Program in Biomedical Engineering, University of Minnesota, Minneapolis, MN 55455, USA. ${ }^{2}$ Institute for Translational Neuroscience, University of Minnesota, Minneapolis, MN 55455, USA.

Published: 18 December 2015

\section{References}

1. Volkmann J, Moro E, Pahwa R: Basic algorithms for the programming of deep brain stimulation in Parkinson's disease. Mov Disord 2006, 21(Suppl 1):S284-S289

2. Johnson MD, Miocinovic S, Mcintyre CC, Vitek JL: Mechanisms and Targets of Deep Brain Stimulation in Movement Disorders 2008, 5(April):294-308.

3. Agnesi F, Connolly AT, Baker KB, Vitek JL, Johnson MD: Deep brain stimulation imposes complex informational lesions. PLoS One 2013, 8 : e74462.

4. Cooper SE, Noecker AM, Abboud H, Vitek JL, Mclntyre CC: Return of bradykinesia after subthalamic stimulation ceases: relationship to electrode location. Exp Neurol 2011, 231:207-13.

5. Tass P a, Qin L, Hauptmann C, Dovero S, Bezard E, Boraud T, Meissner WG Coordinated reset has sustained aftereffects in Parkinsonian monkeys. Ann Neurol 2012, 72:816-20.

6. Adamchic I, Hauptmann C, Barnikol UB, Pawelczyk N, Popovych O, Barnikol TT, Silchenko A, Volkmann J, Deuschl G, Meissner WG, Maarouf M, Sturm V, Freund H-J, Tass PA: Coordinated reset neuromodulation for Parkinson's disease: Proof-of-concept study. Mov Disord 2014, 29:1679-84.

7. Hahn PJ, Mclntyre CC: Modeling shifts in the rate and pattern of subthalamopallidal network activity during deep brain stimulation. J Comput Neurosci 2010, 28:425-41.

8. Badoual M, Zou Q, Davison AP, Rudolph M, Bal T, Frégnac Y, Destexhe A: Biophysical and phenomenological models of multiple spike interactions in spike-timing dependent plasticity. Int I Neural Syst 2006, 16:79-97.

doi:10.1186/1471-2202-16-S1-P83

Cite this article as: Grado et al:: Effects of spike-time dependent plasticity on deep brain stimulation of the basal ganglia for treatment of Parkinson's disease. BMC Neuroscience 2015 16(Suppl 1):P83. 